\title{
Reintubation following planned extubation: incidence, mortality and risk factors
}

\author{
D Whitmore, ${ }^{*}$ T Mahambray \\ From ESICM LIVES 2015 \\ Berlin, Germany. 3-7 October 2015
}

\section{Introduction}

Studies indicate reintubation rates following planned extubation to be between $10-20 \%$ in the general ICU population. There is evidence that extubation failure and reintubation can worsen outcome, with studies suggesting ICU mortality rates of between $25-50 \%$ in these patients.

\section{Objectives}

To establish how our failed extubation rate and subsequent mortality compare to previously published studies, whilst assessing the impact of previously proposed risk factors for extubation failure.

\section{Methods}

In this retrospective case note study we looked at the outcome of each extubation between 1st October 2013 and 30th September 2014. We included all patients $>18$ years of age invasively ventilated for $>48$ hours. We excluded patients proceeding directly to tracheostomy or extubated for withdrawal of care. Failed extubation was defined as the need for reintubation within 5 days of planned extubation. Data was analysed in two groups; 'success' and 'failure' of extubation.

\section{Results}

180 patients were initially included in the study, with 105 remaining once exclusion criteria had been applied. There were a total of 141 extubations with a failure rate of $38 \%$. Those in the 'failure' group had a median length of ICU stay of 14.9 days vs. 8.2 days in the 'success' group. The ICU mortality in these groups being $10 \%$ vs $8 \%$ respectively.

In relation to risk factors for extubation failure, there were no clinically significant differences between the 'failure' and 'success' groups in terms of: age (58 vs 57 yrs); duration of IPPV (3.3 vs 4 days); fluid balance (+ve 2047 vs 2386 mls.); RSBI (50 vs 36) and APACHE II scores (15 vs 17) respectively. However, $90 \%$ of patients with a RSBI $>100$ immediately prior to extubation did subsequently require reintubation.

Emergency non-invasive ventilation was commenced in $10 \%$ of patients post extubation, with $70 \%$ subsequently requiring reintubation. The reasons for extubation failure were difficult to determine, but upper airway obstruction was documented as a contributing factor in $19 \%$ of failed extubations.

\section{Conclusions}

Reintubation post failed extubation is associated with a prolonged ICU stay, but in our patient population had no impact on ICU mortality. Extubation failure is difficult to predict although a RSBI $>100$ at the time of extubation appears to place patients at particularly high risk. The use of emergency NIV post extubation has a high failure rate and should not delay reintubation when necessary. Upper airway obstruction still appears to be an important cause of extubation failure and we would recommend a 'cuff leak' test prior to extubation.

Published: 1 October 2015

\section{References}

1. Thille A, Richard JC, Brochard L, et al: The decision to extubate in the Intensive Care Unit. Am J Resp Crit Care Med 2013, 187:1294-1302.

2. Frutos-Vivar F, Esteban A, Apezteguia C, et al: Outcome of reintubated patients after scheduled extubation. J Crit Care 2011, 26:502-509.

doi:10.1186/2197-425X-3-S1-A684

Cite this article as: Whitmore and Mahambray: Reintubation following planned extubation: incidence, mortality and risk factors. Intensive Care Medicine Experimental 2015 3(Suppl 1):A684. 